\title{
Nursing in cardiology: state of the art and frontiers of knowledge
}

\author{
Alba Lúcia Bottura Leite de Barros', Agueda Maria Ruiz Zimmer Cavalcante' \\ ' Universidade Federal de São Paulo, Paulista Nursing School. São Paulo, Brasil.
}

\author{
How to cite this article: \\ Barros ALBL, Cavalcante AMRZ. Nursing in cardiology: \\ state of the art and frontiers of knowledge. Rev Bras Enferm [Internet]. 2017;70(3):451-2. \\ DOI: http://dx.doi.org/10.1590/0034-7167.2017700301
}

Heart diseases lead the group of clinical disorders with higher rates of hospitalization and mortality and present a progressive increase in incidence due to population ageing, simultaneously to the development of new health therapies and technology. DATASUS ${ }^{(1)}$ estimated a cost of nearly 700 million Reais $^{1}$ for the country's health care system in 2015, only for people with heart failure and acute myocardial infarction.

Generally, people diagnosed with heart diseases have their functional capacity and quality of life impaired. When in children, these diseases can lead to an impaired development, since they can cause systemic injuries and result in disabilities.

Given this situation, nurses have been facing several challenges and, as a consequence, achieved results that place them in a prominent role in different dimensions of care. An example is national and international guidelines that credit the nurses with the benefits brought to the patients during follow-up in disease management and educational programs. The development and validation of scales and measurement instruments helps nurses to establish actions and to make decisions that aim at improving the health care process for the patient. Recent advances in cardiology also stand out, since nurses' appropriation of knowledge through researches and understanding of diseases, treatments and clinical manifestations lead to empowerment in debates and clinical discussions with the healthcare team.

Despite the wide possibilities and the necessity of nurses' work, health care environments are marked by challenging variables such as shortage of workforce, physical structure, equipment and material; inadequate salaries; double working hours; constant physical effort; and the risk of accidents. These situations indicate gaps in the quality of care, often revealing a pattern of decline in health outcomes. Considering this situation, possibly similar in different parts of the world, how can we create a promising future for cardiac nursing?

We observed that there is a lack of nursing interventions that could consolidate the path of the profession, leading to a mastery of evidence-based nursing, focused on previously established objectives. There is a need for the implementation of actions that will demonstrate a nursing performance aware of its role, centered in the patient and in the family; actions performed through coherent judgment, contesting results obtained.

Considering the constant updates in cardiology, there is still a need for technological improvement for the safe handling of devices and equipment, also addressing their risks and benefits. The appropriation of nursing phenomena elements should address actions to search for knowledge and development of the subject, avoiding the hegemony of the biomedical model, necessary for the good conduct of the nursing professional ${ }^{(2)}$. However, the predominance or exclusive use of this model misrepresents the professional, impairing the progress of nursing science.

In a visionary process of professional growth in cardiology, studies addressing nursing diagnoses and the best interventions, allow nurses the appropriation of the knowledge and the development of the nursing science

1 Reais is the Brazilian currency. $\mathrm{R} \$ 1,00$ real corresponds to $\cup \$ 0,32$ cents of a dollar according to the Central Bank of

Brazil on March 25 $5^{\text {th }}, 2017$. 
should be encouraged. Studies addressing diagnostic accuracy studies, taxonomy and identification of new phenomena contribute to the consolidation of the nursing body of knowledge; studies on the applicability and effectiveness of interventions with positive outcomes add visibility and ensure optimal standards of care.

There is an urgent need to reduce the gap between health care at the hospital and at primary services, providing continuing education to the nursing care consumer and, as a consequence, leading to behavioral changes and self-management of disease. In order to achieve this, innovative models such as outpatient consultations, telephone consultations, coaching techniques and individual training should be implemented ${ }^{(3)}$. In secondary prevention actions in different health care settings, nursing professionals should be made aware of technologies such as mobile applications and web pages ${ }^{(3)}$.

Advances in cardiac nursing knowledge have been progressively achieved, cooperating for a safe management of health conditions. However, focus on the role played by the nurse should not be lost, aiming at the appropriation of nursing subject phenomena, which will consolidate the development of the professional.

\section{REFERENCES}

1. Brasil. Ministério da Saúde. DATASUS. Informações de Saúde [Internet]. 2015 [cited 2016 Oct 02]; Available from: http://tabnet.datasus.gov.br

2. Carvalho V. [Research lines in nursing: phylosophical and epistemological highlights]. Rev Bras Enferm [Internet]; 2015 [cited 2016 Oct 02];68(4):723-9. Available from: http://www.scielo.br/pdf/reben/v68n4/0034-7167-reben-68-04-0723. pdf Portuguese.

3. Klopper HC, Hill M. Global Advisory Panel on the Future of Nursing (GAPFON) and Global Health. J Nurs Scholarship [Internet]. 2015 [cited 2016 Oct 02];47:1-4. Available from: http://onlinelibrary.wiley.com/ doi/10.1111/jnu.12118/abstract 